\title{
Desain Ope rasional Prosedur Pemeliharaan dan Perawatan pada Gedung Summarecon Digital Center (SDC) Ditinjau Dari Keandalan Bangunan
}

\author{
Iswanto, Lidia Agustina, Taufik Hamzah dan Antonius Sis wanto \\ Jurusan Teknik Sipil Jl. Gegerkalong Hilir, Ds. Ciwaru ga Kotak Pos 1234 Bandung 40012 \\ E-mail: Iswanto.keto@gmail.com
}

\begin{abstract}
ABSTRAK
Gedung Summarecon Digital Center (SDC) merupakan bangunan yang baru beroperasi dan belum tersediannya acuan pemeliharaan dan perawatan gedung, untuk itu Penelitian ini mengkaji pemeliharaan dan perawatan yang ditinjau dari keandalan bangunan. Dalam hal ini dilakukan dua langkah untuk menyelesaikan masalah tersebut. Pertama yaitu melakukan inspeksi lapangan untuk mengetahui kondisi bangunan secara visual, pengukuran intensitas cahaya, pengukuran tingkat suhu, pengukuran kelembaban, keseragaman beton pada lantai beton basement dan pengukuran retak eksisting. Kedua yaitu dengan analisis deskriptif untuk mengevaluasi ko mponen yang ditinjau dan dibandingakan dengan acuan, mengenai aspek keselamatan, aspek kesehatan dan aspek kenyamanan. Selain itu, untuk memenuhi keandalan bangunan telah dibuat desain operasional prosedur pemeliharaan dan perawatan bangunan dalam bentuk matriks serta membuat formulir untuk ceklisnya. Penelitian in i juga telah menghitung besarnya Life Cycle Cost secara sederhana selama kurun waktu 30 tahun, dalam penentuan LCC ini menggunakan metode Net Present Value yang mengahasilkan nilai LCC sebesar Rp. 2.224.532.589.590.
\end{abstract}

Kata Kunci: Keandalan Bangunan, Pemeliharaan dan Perawatan.

\section{PENDAHULUAN}

Undang-undang No. 28 Tahun 2002 juga menjelaskan bahwa bangunan gedung harus memenuhi syarat administrasi dan teknis, sehingga laik fungsi. Dalam praktek di lapangan banyak pihak yang belum menerapkan peraturan sebagai mana mestinya. Salah satu syarat bangunan gedung yaitu mengenai syarat teknis, seperti tata guna bangunan dan keandalan bangunan. Untuk menjamin terwujudnya bangunan gedung yang andal harus memperhatikan syarat bangunan gedung meliputi aspek keselamatan, aspek kesehatan dan aspek kemudahan Agar fungsi dari bangunan tidak berkurang dan dapat diopersikan sepanjang umur yang telah ditentukan dan sesuai dengan spesifikasi awal maka perlu adanya penanganan serta pengelolaan yang baik yaitu dengan pemeliharaan dan perawatan bangunan.
Bangunan komersial difungsikan untuk mewadahi aktivitas komersial atau kegiatan usaha yang bertujuan mendatangkan keuntungan, agar keuntungan tersebut dapat tercapai perlu dilaku kan perencanaan teknis maupun non-teknis secara baik agar lebih efektif dan efisien. Oleh karena itu perlu adanya suatu pedoman/acuan operasional prosedur pemeliharaan dan perawatan bangunan gedung. SDC merupakan pusat perniagaan yang menyediakan segala kebutuhan teknologi informatika seperti beragam peralatan komputer, gadget dan juga teknologi mobile lainnya, SDC juga merupakan satu-satunya gedung yang menjual barang-barang elektronik di area gading serpong, Tangerang selatan. Pada kondisi saat ini, bangunan SDC menunjukan adanya defect komponen gedung dibuktikan dengan terjadinya beberapa kerusakan komponen gedung seperti pada Gambar 1. dan adanya komplain baik itu dari tenant ataupun customer mengenai tidak nyamannya kondisi gedung. 

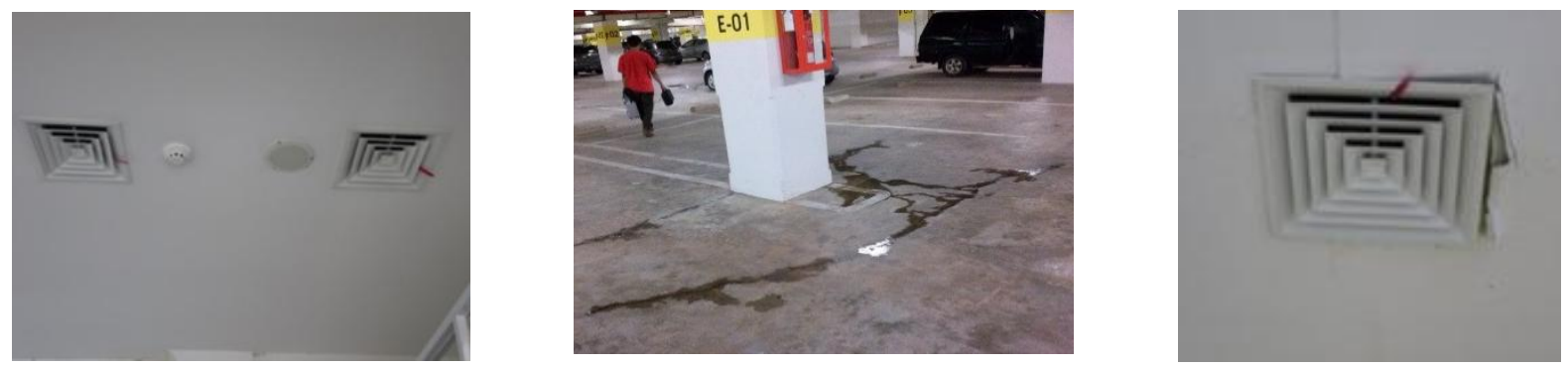

Gambar 1.Deffect pada Beberapa Komponen

Maka dari itu perlu adanya suatu kajian mengenai pemeliharaan dan perawatan yang ditinjau dari keandalan bangunan. Mengingat gedung SDC merupakan gedung yang baru beroperasi dan belum tersedianya pedoman pemeliharaan dan perawatan gedung. SDC merupakan gedung swasta yang memperhatikan profit oriented maka dilakukan analisis biaya hidup guna mengendalikan biaya perusahaan dalam menekan biaya pengeluaran dan meningkatkan keuntungan. Oleh karena itu, perlu dilakukan pembahasan mengenai analisa Life Cycle Cost (LCC) secara sederhanauntuk mengetahui katagori biaya apa saja yang terdapat dalam pengoperasian gedung SDC dan dapat mengetahui seberapa besar total biaya yang dikeluarkan oleh bangunan komersil yaitu mal, mulai tahap desain sampai dengan usia yang ditetapkan.

\subsection{Tujuan Penelitian Ini}

Tujuan dari Penelitian ini adalah:

1. Mengevaluasi kondisi eksisting komponenkomponen gedung yang ditinjau terkait keandalan bangunan.

2. Mendesain prosedur dan metoda peme liharaan gedung SDC pada komponen yang ditinjau dalam bentuk matriks.

3. Mendesain form checklist pemeliharaan dan perawatan pada gedung SDC pada komponen yang ditinjau dalam bentuk matriks .

4. Menentukan Besaran Biaya LCC dalam kurun waktu 30 tahun secara sederhana

\section{TINJAUAN PUS TAKA}

\subsection{Pemeliharaan dan Perawatan Gedung}

Menurut peraturan menteri pekerjaan umum nomor: 24/PRT/M/2008 tentang Pedoman Pemeliharaan dan Perawatan Bangunan Gedung, pengertian pemeliharan bangunan gedung adalah kegiatan menjaga keandalan bangunan gedung beserta prasarana dan sarananya agar bangunan gedung selalu laik fungsi (preventive maintenance) dan pengertian perawatan bangunan gedung adalah kegiatan memperbaiki dan/atau mengganti bagian bangunan gedung, komponen, bahan bangunan, dan/atau prasarana dan sarana agar bangunan gedung tetap laik fungsi (currative maintenance), perawatan dilakukan setelah ada kerusakan atau masalah, baik pada tingkat ringan, sedang, ataupun berat.

\subsection{Keandal an Bangunan Gedung}

Menurut UU No.28 Tahun 2002 yang dimaksud keandalan bangunan gedung adalah keadaan bangunan gedung yang memenuhi persyaratan keselamatan, kesehatan, kenyamanan dan kemudahan bangunan gedung sesuai dengan kebutuhan fungsi yang telah ditetapkan. Untuk menilai keandalan bangunan yaitu menggunakan proses interprestasi yang mengacu pada Petunjuk Teknis Pemeriksaan Keandalan Bangunan PU Cipta Karya 2008, interpretasi ini terdiri dari 3 (tiga) yaitu andal, ku rang andal dan tidak andal.

\subsection{Penentuan LCC deng an Metode NPV}

Perhitungan LCC dilakukan yaitu perhitungan biaya siklus hidup selama 30 tahun. Hal ini merujuk kepada hasil penelitian yang telah dilakukan oleh Nathan \& Morgan (1999) yang telah menyarankan bahwa perhitungan life cycle cost sebaiknya dilakukan untuk 30 tahun. Perhitungan LCC yang dilakukan adalah sebagai berikut:

$\mathrm{NPV}=$ Investasi Awal + NCF dari Tahun Ke-1 s/d $\mathrm{Ke}-30$

Profit Se lama 30 Tahun $=$ NPV $-\mathrm{NCF}$

\section{METODOLOGI}

Metodologi yang digunakan pada penelitian ini yaitu melakukan studi dengan metode analisis deskriptif kuantitatif dengan mengolah data deskriptif dan data kuantitatif. Penelitian ini terdiri atas tiga tahapan yaitu tahap persiapan, tahap 
pengumpulan data dan tahap pembahasan. Tahapan penyelesaian tersebut ditampilkan dalam Gambar 2.

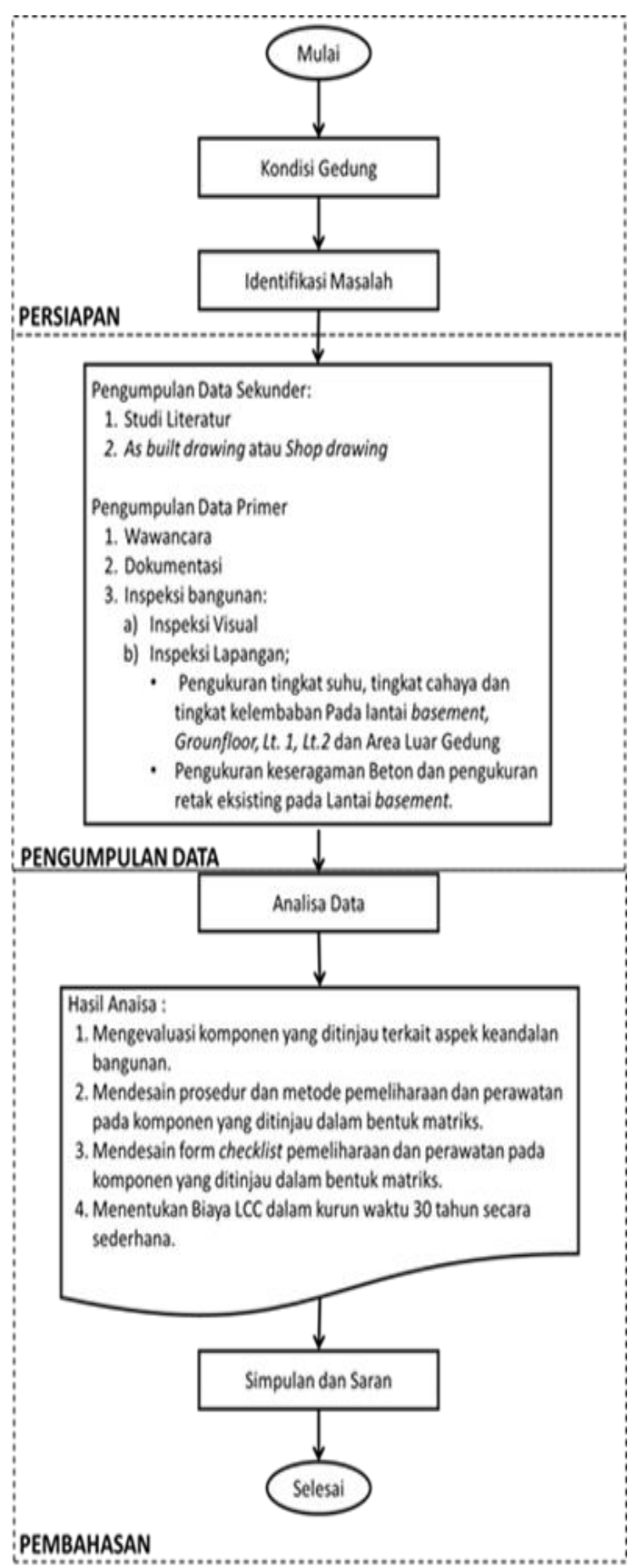

Gambar 2. Flowchart Pelaksanaan Penelitian

\section{HAS IL DAN PEMBAHASAN}

\subsection{Aspek Keselamatan $B$ angunan}

Menurut Mahmudah (2012), salah satu standar penting yang ditetapkan Badan Standarisasi Nasional dalam Standar Nasional Indonesia mengenai perlindungan terhadap bahaya kebakaran pada bangunan bertingkat. Sistem kebakaran harus direncanakan dari awal pembangunan konstruksi gedung, khususnya untuk sistem proteksi aktif meliputi tata letak dan spesifikasi material peralatan fire fighting seperti sprinkler, heat detector, smoke detector, hydrant.

Evaluasi sistem proteksi aktif terdiri dari kebutuhan jumlah dan peletakan proteksi aktif. Sistem proteksi kebakaran aktif merupakan sistem proteksi kebakaran yang secara lengkap terdiri atas sistem pendeteksian kebakaran baik manual ataupun otomatis, sistem pemadam kebakaran berbasis air seperti sprinkler, hydrant dan sistem pemadam kebakaran berbasis bahan kimia, seperti APAR (Alat Pemadam Api Ringan).

Evaluasi sistem proteksi pasif, sistem proteksi pasif merupakan suatu sistem proteksi kebakaran pada bangunan gedung yang berbasis pada desain struktur dan arsitektur sehingga bangunan gedung tersebut secara struktur stabil dalam waktu tertentu dan dapat menghambat penjalaran api serta panas bila terjadi kebakaran.

\subsection{Evaluasi Sistem Kebakaran}

Evaluasi Sistem Kebakaran yaitu dengan observasi lapangan menggunakan meteran dan wawancara departemen fire safety. Dari data yang telah dianalis menunut SNI, gedung Summarecon Digital Center (SDC) ini termasuk pada bangunan Kelas VI (bangunan gedung perdagangan). Dengan jumlah lantai total yaitu 5 lantai bangunan dan ketinggian setiap lantai 3,8 meter, maka bangunan diklasifikasikan kedalam Tipe A. Adapun penilaian evaluasi detector kebakarangedung yang mengacu pada SNI dan mengacu pada penilaian sesuai dengan pedoman pemeriksaan keselamatan bangunan gedung (Pd-T11-2005), dapat dilihat pada Tabell. 
Tabel 1.Pemenuhan Kriteria Penilaian Evaluasi Sistem Kebakaran

\begin{tabular}{|c|c|c|c|}
\hline No & Acuan/S tandar & Kondisi Aktual & Keterangan \\
\hline & \multicolumn{3}{|c|}{ Sistem Alarm dan Deteksi Kebakaran (Heat Detetctor \& Smoke Detector) } \\
\hline \multirow[t]{2}{*}{1} & $\begin{array}{l}\text { Pd-T-11-2005-C } \rightarrow \text { Terdapat detektor (smoke } \\
\text { detektor/heat detector) kebak aran y ang dipasang di } \\
\text { seluruh ruangan }\end{array}$ & $\begin{array}{l}\text { Terdap at Smoke detector kebakaran } \\
\text { y ang dip asang di seluruh ruangan }\end{array}$ & $\begin{array}{l}\text { Smoke Detector sudah } \\
\text { terpasang di seluruh ruangan } \\
\text { sehingga sesuai }\end{array}$ \\
\hline & \multicolumn{3}{|l|}{ Alat Pemadam Api Ringan (APAR) } \\
\hline \multirow[t]{2}{*}{2} & $\begin{array}{l}\text { SNI 03-3987-1995 } \rightarrow \text { Setiap ruangan tertutup dengan } \\
\text { luas tidak lebih dari } 250 \mathrm{~m}^{2} \text { harus dilen gkapi den gan } \\
\text { sekurang-kuran gny a sebuah APAR berukuran } 2 \mathrm{~kg} \\
\text { sesuai klasifik asi isi ruangan }\end{array}$ & $\begin{array}{l}\text { Sesuai den gan buku pedoman fit out } \\
\text { SDC APAR harus dipasang setiap } 100 \\
\mathrm{~m}^{2} \text { dengan ukuran } 3,5 \mathrm{~kg}\end{array}$ & $\begin{array}{l}\text { APAR dipasang setiap } 100 \mathrm{~m}^{2} \\
\text { dengan ukuran } 3.5 \mathrm{~kg} \text { S esuai } \\
\text { dengan acuan karen a ruangan } \\
\text { dengan luas }<250 \mathrm{~m} 2 \text { harus } \\
\text { ada sebuah }>2 \mathrm{~kg}\end{array}$ \\
\hline & \multicolumn{3}{|l|}{ Hydrant } \\
\hline \multirow[t]{2}{*}{3} & $\begin{array}{l}\text { Pd-T-11-2005-C } \rightarrow \text { Hydrant halaman (pilar) ditempatkan } \\
\text { di luar ban gunan pada lokasi y ang aman dari api dan } \\
\text { peny aluran pasokan air ke dalam ban gun an dilakukan } \\
\text { melalui katup Siamese }\end{array}$ & $\begin{array}{l}\text { Jarak letak hydrant halaman den gan } \\
\text { gedung } \pm 10 \text { meter, }\end{array}$ & $\begin{array}{l}\text { Hydrant halaman dengan } \\
\text { gedung berjarak } \pm 10 \text { meter, } \\
\text { sehingga sesuai dengan acuan }\end{array}$ \\
\hline & \multicolumn{3}{|l|}{ S prinkler } \\
\hline \multirow[t]{2}{*}{4} & $\begin{array}{l}\text { Menteri Pekerjaan Umum nomor 02/KPTS/1985 } \rightarrow \\
\text { Jumlah dan jenis sesuai den gan persyaratan }\end{array}$ & $\begin{array}{l}\text { Jumlah dan jenis men gacu pada } \\
\text { persy aratan terlihat pada Tabel IV.16 }\end{array}$ & Sudah sesuai dengan acuan \\
\hline & \multicolumn{3}{|l|}{ Jalur Evakuasi } \\
\hline \multirow[t]{2}{*}{5} & Permen No. 26/PRT/M/2008 $\rightarrow$ Jumlah jalur evakuasi & $\begin{array}{l}\text { Jumlah jalur evakuasi melebihi y ang } \\
\text { disyaratkan }\end{array}$ & Sudah sesuai dengan acuan \\
\hline & \multicolumn{3}{|l|}{ Koridor } \\
\hline \multirow[t]{2}{*}{6} & $\begin{array}{l}\text { Kepmen PU No. 10/KPTS/2000 } \rightarrow \text { Kepmen PU No. } \\
\text { 10/KPTS/2000 Lebar bersih minimal } 2 \text { meter }\end{array}$ & $\begin{array}{l}\text { Lebar koridor melebihi y ang } \\
\text { disyaratkan }\end{array}$ & Sudah sesuai dengan acuan \\
\hline & \multicolumn{3}{|l|}{ Pintu Darurat } \\
\hline \multirow[t]{2}{*}{7} & $\begin{array}{l}\text { SNI 03-1746-2000 } \rightarrow \text { Ukuran pintu darurat minimum, } \\
\text { lebar } 80 \mathrm{~cm} \text { dan tinggi } 2 \text { meter }\end{array}$ & $\begin{array}{l}\text { Ukuran pintu pada SDC lebar } 1 \mathrm{~m} \text { dan } \\
\text { tinggi pintu } 2.10 \mathrm{~m}\end{array}$ & Sudah sesuai dengan acuan \\
\hline & \multicolumn{3}{|l|}{ Tangga Darurat } \\
\hline 8 & $\begin{array}{l}\text { SNI 03-1746-2000 } \rightarrow \text { Lebar injak an } 28 \mathrm{~cm} \text { dan tinggi } \\
\text { anak tangga minimum } 10 \mathrm{~cm} \text { dan maksimum } 18 \mathrm{~cm}\end{array}$ & $\begin{array}{l}\text { Lebar injakan } 28 \mathrm{~cm} \text { dan tinggi anak } \\
\text { tangga } 17,5 \mathrm{~cm}\end{array}$ & Sudah sesuai dengan acuan \\
\hline
\end{tabular}

\subsection{Pemeliharaan dan Perawatan Aspek Keselamatan Terhadap Sistem Kebak aran}

Tabel 2. Pemeliharaan dan Perawatan Aspek Keselamatan Terhadap Sistem Kebakaran

\begin{tabular}{|c|c|c|c|c|c|c|c|c|c|c|}
\hline \multirow[b]{2}{*}{ NO } & \multirow[b]{2}{*}{ Acuan } & \multirow[b]{2}{*}{$\begin{array}{l}\text { Kegiatan / } \\
\text { Tindakan }\end{array}$} & \multicolumn{7}{|c|}{ Rentang Waktu } & \multirow[b]{2}{*}{ Keterangan } \\
\hline & & & 䨌 & 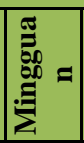 & 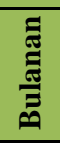 & ले & 蔦 & n & 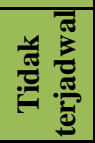 & \\
\hline 1 & $\begin{array}{c}\text { Pd-T-11- } \\
\text { 2005-C } \rightarrow \\
\text { Smoke } \\
\text { Detector }\end{array}$ & $\begin{array}{l}\text { Inspeksi } \\
\text { visual dan } \\
\text { pengujian }\end{array}$ & $\mathrm{v}$ & & & & & & & $\begin{array}{l}\text { Harus dilakukan inspeksi visual kondisi den gan men gecek } \\
\text { visual keadaan smoke detektor danmengecek visual } \\
\text { kebersihan tutup smoke detektor. Dalam inspeksi visual } \\
\text { team kerja (engeener) membawa form checklist } \\
\text { pemeriksaan fire safety dan mencatat kondisi ny ata, y ang } \\
\text { meliputi jumlah smoke detector perlokasi dan mencatat } \\
\text { smoke detector y ang cacat/rusak/kotor/tidak berfungsi. }\end{array}$ \\
\hline \multirow[b]{2}{*}{ NO } & \multirow[b]{2}{*}{ Acuan } & \multirow[b]{2}{*}{$\begin{array}{l}\text { Kegiatan / } \\
\text { Tindakan }\end{array}$} & \multicolumn{7}{|c|}{ Rentang Waktu } & \multirow[b]{2}{*}{ Keterangan } \\
\hline & & & 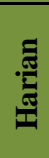 & 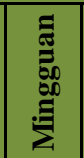 & 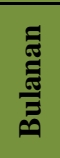 & ஸे & 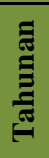 & in & 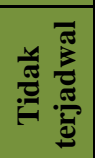 & \\
\hline
\end{tabular}




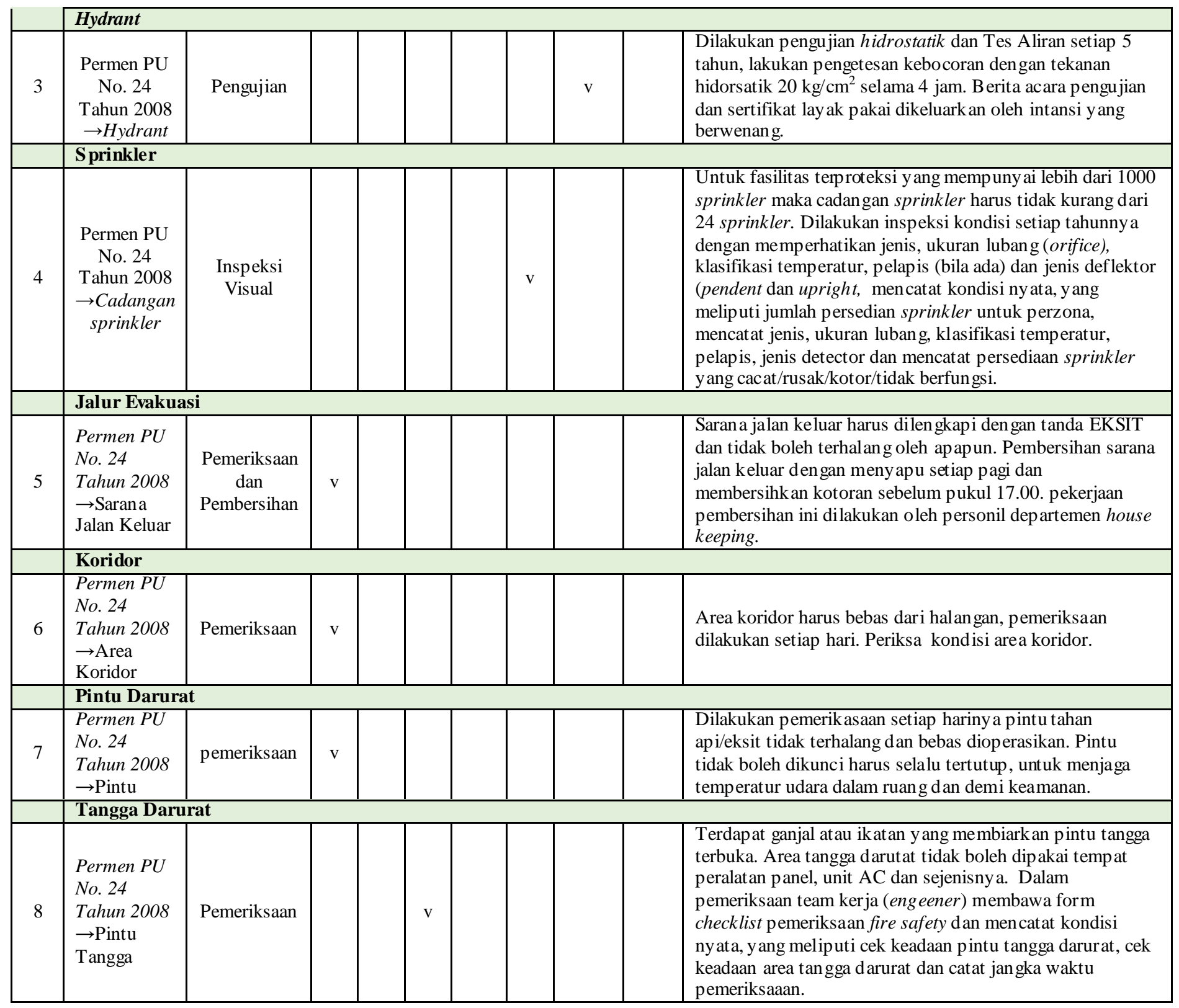

\subsection{Aspek Kesehatan B angunan}

Menurut Permen PU No.24 tahun 2008, persyaratan kesehatanbangunan gedung meliputi persyaratan intensitas cahaya, intensitas suhu, dan sistem plambing. Tetapi yang akan di evaluasi di gedung SDCini yaitu Evaluasi Pencahayaan, Suhu dan Kele mbapan.

\subsection{Intensitas Cahaya}

Pengukuran intensitas pencahayaan dilakukan ketika lampu menyala, dikarenakan fungsi bangunan yang beroperasi selama 20 jam dan sulitnya mendapatkan perizinan untuk mematikan lampu pada saat bangunan beroperasi. Dilakukan pengukuran intensitas pencahayaan di Lantai 2, lantai 1, Lantai groundfloor dan Lantai Basement. Secara keseluruhan, intensitas pencahayaan di lantai Groundfloor telah sesuai dengan rekomendasi SNI 6197-2011 yang membahas mengenai konservasi energi pada sistem pencahayaan. Seperti yang ada pada area supermarket yang didalamnya terdapat berbagai barang jualan seperti buah - buahan, alat tulis, kasir dan koridor. Intensitas pencahayaan di area tersebut relatif telah memenuhi standar yang direko mendasikan oleh SNI. 


\subsection{Intensitas Suhu}

Dilakukan pengukuran intensitas suhu ruangan di beberapa titik sebagai sample. Penempatan titiktitik tersebut disamakan dengan pengukuran intensitas pencahayaan. Untuk pengkondisian udara di Mal SDC menggunakan sistem HVAC. Hal tersebut direncanakan dengan beberapa pertimbangan seperti fungsi ruangan, data suhu luar ruangan beserta perbandingan dengan suhu dalam ruangan, tingkat temperatur luar yang tinggi serta kondisi thermal kenyamanan suhu manusia. Namun pada aplikasinya seharusnya terdapat beberapa area yang bisa menggunakan luas bukaan dan sinar matahari langsung untuk digunakan sebagai suhu alami ruangan.

Dilakukan pengukuran intensitas suhudi Lantai 2, lantai 1, Lantai groundfloor dan Lantai Basement.Untuk intensitas suhulantai 2 secara keseluruhan telah memenuhi persyaratan dengan tingkat penghawaan rata - rata mencapai $25^{\circ} \mathrm{C}$. Pengkondisian rata rata di area lantai 2 termasuk kedalam kategori nyaman dengan tingkat penghawaan rata - rata berkisar antara $22,8^{\circ} \mathrm{C}$ $25,8^{\circ}$ C.Namun untuk pengefektifan suhu alami sebenarnya dapat menggunakan luas bukaan sebagai sumber penghawaan selain menggunakan HVAC. Pada area lapangan futsal menggunakan beberapa buah kipas angin sebagai penghawaan buatan di area tersebut. Serta terdapat bukaan yang berfungsi sebagai penerangan dan penghawaan tambahan di lapangan futsal tersebut.

\subsection{Intensitas Kelembaban}

Pada bangunan SDC, tingkat kelembaban rata rata pada beberapa lantai tidak sesuai dengan persyaratan yang direkomendasikan oleh SNI 036572-2001 mengenai tata cara perancangan sistem ventilasi dan pengkondisian udara dimana tingkat kelembaban yang dipersyaratkan yaitu berkisar antara 55\% sampai dengan $60 \%$.

Pada bangunan existing, pengkondisian kelembaban sangat penting untuk diidentifikasi, hal tersebut berpengaruh terhadap finishing sisi eksterior dan interior suatu bangunan. Beberapa pengaruh tingkat kelembaban yang tidak sesuai standar dapat mengakibatkan beberapa efek negatif pada kondisi struktur dan arsitektur bangunan.

\subsection{Sistem Plumbing}

Dari hasil observasi pengelolahan air bersih dan air kotor dilakukan dengan cukup baik, air bersih yang digunakan untuk kebutuhan tenant, mushola begitu pula digunakan untuk kebutuhan fire system. Pada pengelolahan air kotor pun pada gedung SDC limbah air kotor tidak langsung dibuang tetapi dilakukan recycle hingga beberapa tahap dan dapat dimanfaatkan untuk kebutuhan seperti flushing toilet, digunakan untuk kebutuhan chiller dan AHU.

\subsection{Pemeliharaan dan Perawatan As pek Kesehatan}

Tabel3. Pemeliharaan dan Perawatan Aspek Kesehatan

\begin{tabular}{|c|c|c|c|c|c|c|c|c|c|c|}
\hline \multirow[b]{2}{*}{ NO } & \multirow[b]{2}{*}{ Acuan } & \multirow[b]{2}{*}{$\begin{array}{l}\text { Kegiatan/ } \\
\text { Tindakan }\end{array}$} & \multicolumn{7}{|c|}{ Rentang Waktu } & \multirow[b]{2}{*}{ Keterangan } \\
\hline & & & 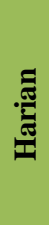 & 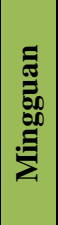 & 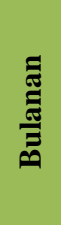 & 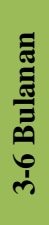 & 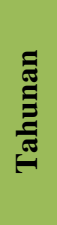 & 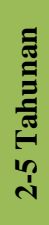 & 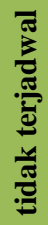 & \\
\hline & \multicolumn{10}{|c|}{ Intensitas Cahaya } \\
\hline 1 & $\begin{array}{c}\text { Permen PU } \\
\text { No. } \\
\text { 28/PRT/M/ } \\
2008 \\
\rightarrow \text { Sistem } \\
\text { penerangan } \\
\text { dan sistem } \\
\text { kontrol }\end{array}$ & $\begin{array}{c}\text { Pemeriksaan } \\
\text { peralatan } \\
\text { dan spare } \\
\text { part }\end{array}$ & & & & $\mathrm{v}$ & & & $\mathrm{v}$ & $\begin{array}{l}\text { Pemeriksaaan kelengkapan peralatan dan } \\
\text { spare part, Dalam pemeriksaaan team kerja } \\
\text { (engeener) membawa form checklist instalasi } \\
\text { listrik dan mencatat kondisi nyata, y ang } \\
\text { meliputi catat keadaan peralatan dan spare } \\
\text { part, ganti apabila terjadi kerusakan dan catat } \\
\text { waktu pemeriksaaan. }\end{array}$ \\
\hline
\end{tabular}




\begin{tabular}{|c|c|c|c|c|c|c|c|c|c|c|}
\hline \multirow[b]{2}{*}{ NO } & \multirow[b]{2}{*}{ Acuan } & \multirow[b]{2}{*}{$\begin{array}{l}\text { Kegiatan/ } \\
\text { Tindakan }\end{array}$} & \multicolumn{7}{|c|}{ Rentang Waktu } & \multirow[b]{2}{*}{ Keterangan } \\
\hline & & & 馬 & 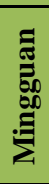 & 音 & ڤై & 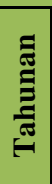 & 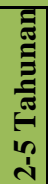 & 焉 & \\
\hline & \multicolumn{10}{|c|}{ Intensitas Suhu dan Kelembaban } \\
\hline & $\begin{array}{l}\text { Permen PU } \\
\text { No. } \\
\text { 28/PRT/M/ } \\
2008 \\
\rightarrow \text { Chiller }\end{array}$ & $\begin{array}{l}\text { Service di } \\
\text { AHU/FCU }\end{array}$ & & & $\mathrm{v}$ & & & & & $\begin{array}{l}\text { Periksa tekanan air din gin masuk dan keluar } \\
\text { dengan thermometer. Dalam pemeriksaaan } \\
\text { team kerja (engeener) membawa form } \\
\text { checklist dan mencat at kondisi nyata, y ang } \\
\text { meliputi catat hasil pemeriksaan dan catat } \\
\text { waktu pemeriksaan. }\end{array}$ \\
\hline 2 & \multicolumn{10}{|c|}{ Sistem Plumbing } \\
\hline 3 & $\begin{array}{l}\text { Permen PU } \\
\text { No. } \\
\text { 28/PRT/M/ } \\
\text { 2008 } \rightarrow \\
\text { Instalasi Air } \\
\text { Kotor }\end{array}$ & $\begin{array}{l}\text { Pemeriksaan } \\
\text { STP }\end{array}$ & $\mathrm{v}$ & $\mathrm{v}$ & $\mathrm{v}$ & & & & & $\begin{array}{l}\text { Periksa harian kondisi basket screen dan bila } \\
\text { ada kotoran bersihkan, hal ini agar aliran air } \\
\text { limbah dapat lancar ke proses STP. Backwash } \\
\text { sand filter dan karbon filter setiap minggu } \\
\text { atau menurut kondisi filter yang ada, hal ini } \\
\text { dapat dilihat dari tekanan pada pressure } \\
\text { gauge. Pengecekan air limbah ke BPLH tiap } 3 \\
\text { bulan sekali. Dalam pemeriksaaan team kerja } \\
\text { (engeener) membawa form checklist dan } \\
\text { mencatat kondisi ny ata, yang meliputi catat } \\
\text { hasil pemeriksaan dan catat waktu } \\
\text { pemeriksaan. }\end{array}$ \\
\hline
\end{tabular}

\subsection{Aspek Kenyamanan Bangunan}

Evaluasi kenyamanan gedung adalah proses kegiatan untuk mengetahui tingkat kenyamanan gedung, dalam Penelitian ini komponen interior yang dibahas seperti dinding, plafon dan lantai serta eksterior seperti parkir. Metode dalam evaluasi ini yaitu dengan melakukan inspeksi lapangan, sehingga dapat mengetahui informasi data kondisi interior gedung. Inspeksi yang dilakukan dengan mengacu kepada Pedoman Teknis Pemeriksaan Berkala Bangunan Gedung No. 16/PRT/M/2010.

\subsection{Ins peksi Visual}

Metoda pemeriksaan/pengamatan secara visual dilakukan pada lokasi-lokasi kritis yang terindikasi mengalami kerusakan fisik yang dapat terlihat jelas/ diamati. Pengamatan/pemeriksaan ini dilakukan dengan mencatat (menginventarisasi) sebagian atau seluruh kerusakan yang terjadi pada komponen interior (dinding, plafon dan lantai) basement yang disertai pengambilan dokumentasi, sehingga diharapkan semua data-data tersebut dapat tercatat seluruhnya.

\subsection{Non-Destructive Test (NDT)}

NDT adalah aktivitas pengujian atau inspeksi terhadap suatu struktur beton ataupun material lain tanpa merusak. Ada beberapa metode pengujian NDT pada studi ini antara lain, pengujian hammer test, crack width detector dan depth crack detector. Pengujian ini hanya dilakukan pada elemen lantai basement karena dari hasil inspeksi terjadi kerusakan berat yaitu adanya retak dibeberapa tempat dan munculnya rembesan air pada permukaan retakan tersebut.

Berdasarkan hasil pengujian hammer bahwa lantai beton pada basement memiliki mutu yang melebihi rencana artinya dalam hal ini mutu beton aktual tidak mempengaruhi tingkat kerusakan pada lantai beton basement, untuk itu dilakukan pengujian lebar dan kedalaman retak sehingga didapatkam klasifikasi tingkat kerusakana sesuai dengan ACI 224.

Berdasarkan hasil inspeksi lapangan dari hasil pengujian retak eksisting didapat $25 \%$ mengalami retak struktur pada elemen lantai beton, terjadi juga beberapa keretakan pada plafon dan dinding, akan tetapi pada kondisi sekarang gedung dalam masa pemiliharaan oleh pihak kontraktor sehingga data tersebut dapat digunakan untuk memperbaiki memperbaiki komponen yang rusak.

\subsection{Perbaikan Elemen Pelat Lantai}

Berdasarkan hasil inspeksi visual, uji hammer dan pengukuran retak eksisting maka dapat merencanakan perbaikan retak pada elemen pelat lantai. Analisis pemilihan material yang cocok menggunakan bahan material injeksi menggunakan bahan polyurethae, karena bahan 
Vol. 21, No.1, Maret 2019

material tersebut berguna salah satunya untuk menghentikan kebocoran.

Pemeliharaan dan perawatan dilakukan pada ko mponen interior basement untuk me mberikan keindahan dan kenyamanan penghuni dalam berkegiatan di bangunan tersebut, adapun prosedur pemeliharaan dan perawatan komponen interior lantai basement yang mengacu pada Permen PU No. 24 Tahun 2008 dapat dilihat pada Tabel 3 .

\subsection{Pemeliharaan dan Perawatan As pek Kenyamanan}

Tabel. 4. Pe meliharaan dan Perawatan Aspek Kenyamanan

\begin{tabular}{|c|c|c|c|c|c|c|c|c|c|c|c|}
\hline \multirow[b]{2}{*}{ No } & \multirow[b]{2}{*}{ Kondisi } & \multirow[b]{2}{*}{ Foto } & \multirow[b]{2}{*}{$\begin{array}{c}\text { Kegiatan } \\
\text { Pemeliharaan }\end{array}$} & \multicolumn{7}{|c|}{ Rentang Waktu } & \multirow[b]{2}{*}{ Keterangan } \\
\hline & & & & 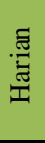 & 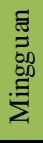 & 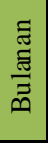 & 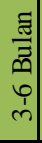 & 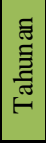 & 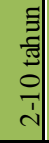 & 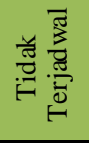 & \\
\hline \multicolumn{12}{|c|}{ Plafond } \\
\hline \multirow{3}{*}{1} & \multirow{3}{*}{$\begin{array}{l}\text { - Spesifikasi : } \\
\text { - } \quad \text { Gypsum board } \\
\quad 9 \mathrm{~mm} \text { ex } \\
\text { jayaboard } \\
\text { - } \quad \text { Finishing : Cat } \\
\quad \text { AEP } \\
\text { - Permukaan plafon } \\
\text { kotor, terdapat } \\
\text { retakan } \\
\text { - Adanya lubang } \\
\text { exhaust pada plafon } \\
\text { belum ditutup }\end{array}$} & & \multirow{3}{*}{$\begin{array}{l}\text { Pembersihan, } \\
\text { Pengecetan } \\
\text { dan } \\
\text { Penggantian }\end{array}$} & & & & $\mathrm{v}$ & & & & $\begin{array}{l}\text { - Pembersihan terhadap debu dan sarang laba- } \\
\text { laba dilakukan } 3 \text { bulan sekali. } \\
\text { - Pekerjaan pembersihan dilakukan oleh Staff } \\
\text { Cleaning Service sedangkan pekerjaan } \\
\text { perbaikan dilakukan oleh staff civil } \\
\text { - Alat dan bahan yang dibutuhkan : sapu, } \\
\text { tongkat panjang dan tangga }\end{array}$ \\
\hline & & & & & & & & & $\mathrm{v}$ & & $\begin{array}{l}\text { - Pengecatan ulang dilakukan 5-8 tahun sekali } \\
\text { (estetika dan perlindungan cuaca) } \\
\text { - Pekerjaan pengecetan dilakukan oleh staff } \\
\text { civil, catat waktu pekerjaan. } \\
\text { - Alat dan bahan yang dibutuhkan : Steger, } \\
\text { roll cat dan cat }\end{array}$ \\
\hline & & & & & & & & & & $\mathrm{v}$ & $\begin{array}{l}\text { - Penggantian dilakukan apabila plafon } \\
\text { gypsum bord rusak akibat terkena air at au } \\
\text { lainnya. plafon harus secepatnya diperbaiki } \\
\text { atau diganti dengan yang baru (estetika). } \\
\text { - Pekerjaan penggantian dilakukan oleh staff } \\
\text { civil, catat waktu ket ika melakukan } \\
\text { penggantian. }\end{array}$ \\
\hline \multicolumn{12}{|c|}{ Lantai } \\
\hline 2 & $\begin{array}{l}\text { - Spesifikasi : } \\
\text { - Beton pelat lantai } \\
\text { parkir f'c : } 30 \mathrm{Mpa} \\
\text { - Floor hardener } \\
\text { - Warna natural } 5 \\
\mathrm{~kg} / \mathrm{m} 2 \text { Ex uzin } \\
\text { - Terjadinya retakan } \\
\text { dibeberapa area dan } \\
\text { munculnya rembesan } \\
\text { air pada permukaan } \\
\text { retak tersebut. } \\
\text { - Permukaan lantai } \\
\text { parkir kotor }\end{array}$ & & $\begin{array}{c}\text { Perbaikan, } \\
\text { pemeriksaan } \\
\text { dan } \\
\text { pemeliharaan }\end{array}$ & & & & & & & $\mathrm{v}$ & $\begin{array}{l}\text { - Apabilaterjadi retak ringan dan sedang } \\
\text { maka dapat menggunakan epoxy grouts dan } \\
\text { apabilaterjadi retak berat harus } \\
\text { diidentifikasi lebih lanjut (estetika). } \\
\text { - Pekerjaan penggantian dilakukan oleh staff } \\
\text { civil, catat waktu ketika melakukan } \\
\text { penggantian. } \\
\text { - Prosedur perbaikan dapat dilihat pada sub } \\
\text { bab 4.4.1.1.bag. c }\end{array}$ \\
\hline
\end{tabular}




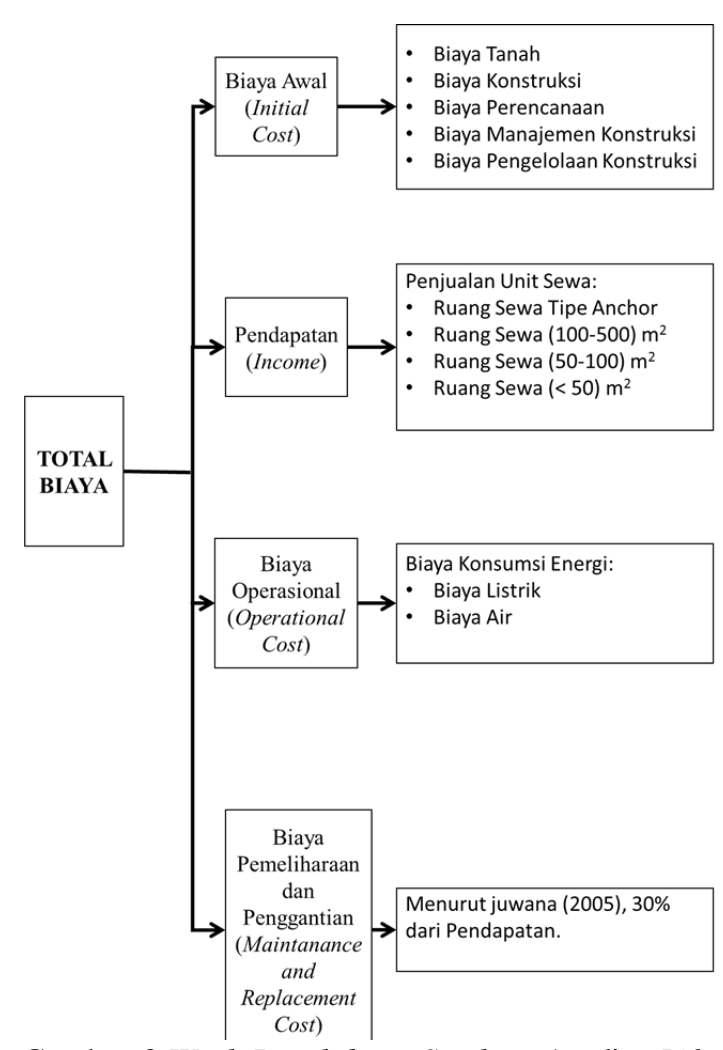

Gambar 3. Work Breakdown Struktur Analis a Life Cycle Cost Gedung SDC

\subsection{Biaya Awal (Initial Cost)}

Biaya awal (initial cost) pada analisa Life Cycle Cost Summarecon Digital Center ini terdiri dari biaya tanah, biaya konstruksi, biaya perencanaan, biaya perizinan, biaya manajemen konstruksi dan biaya pengelolahan Setelah melakukan perhitungan mengenai komponen biaya awal (initial cost), maka dapat disimpulkan bahwa total biaya awal yang dikeluarkan untuk proyek pembagunan SDC ini adalah sebesar Rp. 535.985.766.754.

\subsection{Biaya Pendapatan (Income)}

Biaya pendapatan pada mall Summarecon Digital Center in i berasal dari penjualan unit retail dan counter island. Penjualan ini dilakukan oleh departemen leasing kemudian memberikan tugas kepada departemen fitout dan melayani para tenant. Total penjualan ini merupakan pendapat kotor dari mal SDC, total pendapatan yang dihasilkan oleh penjualan unit sewa/bulan sebesar Rp. 1.117.098.400. Dalam hal ini diasumsikan tidak terjadi kenaikan harga ruang sewa dalam 1 tahun kedepan, sehingga besarnya pendapata dalam 1 tahun sebesar Rp. 13.405.180.800.

\subsection{Biaya Operasional (Operational Cost)}

Biaya operasional terdiri atas biaya penggunaan listrik dan biaya penggunaan air. Biaya operasional ini nantinya akan digunakan dalam memperhitungkan pendapatan bersih mal SDC yaitu dengan pendapatan kotor dikurangi dengan biaya operasional dan biaya pemeliharaan. Untuk tarif dasar listrik PLN tangerang pada tahun 2014 sebesar Rp. 1700/Kwh dan untuk tarif dasar air PDAM tanggerang sebesar Rp. $9000 / \mathrm{m}^{3}$. Dalam hal ini tarif dasar listrik dan tarif dasar air diasumsikan tetap, tidak ada perubahan perbulannya dalam setahun kedepan. Sehingga dapat diketahui biaya operasional selama 1 tahun, Sehingga didapat pengeluaran biaya operasional dari konsumsi energi listrik dan air selama 1 tahun, pada tahun pertama sebesar Rp. 2.107.654.296.

\subsection{Biaya Pemeliharaan dan Penggantian}

Berdasarkan panduan sistem bangunan tinggi untuk arsitek dan prakt isi bangunan tahun 2005, Juwana (2005), biaya pemeliharaan untuk gedung komersil dalam hal ini mal yang digunakan untuk aktifitas perbaikan peralatan, pemeliharaan utilitas, pengecatan ulang dan sebagainya yang dilakukan setiap 1 tahun sekali. Besarnya biaya pemeliharaan pertahun dialokasikan sebesar $30 \%$ dari pendapatan mall, $30 \%$ dari Rp. 13.405.180.800 atau setara dengan Rp. 4.021.554.240. Tentunya biaya pemeliharaan ini akan selalu berubah dalam setiap tahunnya karena faktor dari inflasi.

Untuk biaya penggantian, menurut juwana (2005) besarnya biaya replacement setiap 5 tahun sekali dilakukan sebesar $30 \%$ dari pendapatan gedung mal SDC. Biaya penggantian ini digunakan untuk penggantian peralatan, mesin-mesin, AC dan sebagainya. Biaya replacement $30 \%$ dari Rp. 13 . 405.180.800 yaitu sebesar Rp. 4. 021.554.240. Biaya replacement tentunya akan berubah setiap dalam perhitungannya karena berpengaruh terhadap laju inflasi setiap 5 tahunnya.

\subsection{Penentuan Life Cycle Cost dengan Metoda Net Present Value}

Perhitungan LCC dilakukan yaitu perhitungan biaya siklus hidup selama 30 tahun. Hal ini merujuk kepada penelitian yang telah dilakukan oleh Nathan \& Morgtan (1999) yang menyarankan bahwa perhitungan life cycle cost sebaiknya dilakukan untuk 30 tahun.

Untuk memperkirakaan nilai setiap tahunnya, berdasarkan dari suku bunga yang di dapat dari Bank Indonesia dalam 3 tahun terakhir maka dapat diprediksi setiap tahunnya mengalami kenaikan sebesar 7,59 \%. Sehingga nilai yangakan datang (future value) dapat diprediksi yaitu 
Vol. 21, No.1, Maret 2019

denganmenggunkan persamaan $(2,12)$. Dari hasil perhitungan di atas didapat total LCC dalam kurun waktu 30 tahun untuk mal Summarecon Digital Center adalah sebesar Rp. 1.367.049.300.689. Penerapan LCC pada gedung Summarecon Digital Center pada tahun ke 30 memperoleh keuntungan sebesar Rp. 295.077.767.182, keuntungan tersebut masih kotor karena perhitungan operasional hanya meninjau konsumsi energi tanpa biaya pengeluaran untuk pegawai.

\section{KES IMPULAN}

Hal yang dapat disimpulkan pada pembahsan Penelitian mengenai desain standar operasional prosedur pemeliharaan dan perawatan gedung SDC yang ditinjau dari kenadalan bangunan yaitu sebagai berikut:

1. Evaluasi komponen eksisting pada aspek keselamatan yaitu pada proteksi aktif dan pasif masih mengalami beberapa ketidaksesuaian seperti dari kebutuhan jumlah komponen, spesifikasi, jarak antar komponen, tata letak komponen dan lain sebagainya. Beberapa ketidaksesuaian tersebut di berikan rekomendasi untuk diterapkan sesuai dengan perarturan yang ada. Evaluasi pada aspek kesehatan dan kenyamanan pun masih mengalami ketidaksesuaian dengan perarturan yang berlaku.

2. Tahap mendesain standar operasional pemeliharaan ini sepertidesain rentan waktu perawatan yang dibuat dalam bentuk matriks dan terbagi menjadi 4 bagian yaitu harian, mingguan, bulanan dan tidak terjadwal. Tidak terjadwal khusus dilakukan apabila komponen mengalami kerusakan atau perlu penggantian.

3. Desain Form checklist dibuat agar para engineer lebih mudah mendata tiap komponen keandalan bangunan, dan form checklist juga berguna sebagai riwayat suatu komponen keandalan yang apabila terjadi kerusakan pada komponen tersebut sehingga dapat segera mengetahui penyebab kerusakannya.

4. Dari hasil perhitungan di atas didapat total LCC dalam kurun waktu 30 tahun untuk mal Summarecon Digital Center adalah sebesar Rp. 1.367.049.300.689. Penerapan LCC pada gedung Summarecon Digital Center pada tahun ke 30 memperoleh keuntungan sebesar Rp. 295.077.767.182,

\section{DAFTAR PUSTAKA}

Juwana, Jimmy S. 2005. "Panduan Sistem Bangunan Tinggi”, Jakarta: Erlangga

Marlailana, Elisabeth. 2011. "Manajemen Proyek Perawatan dan Perbaikan Gedung”. Politeknik Negeri Bandung.

Nathan, Coffee \& Morgan. 1999. "Life Cycle Cost Analysis Handbook". Alaska: Department of Education \& Early Development

National Fire Protection Association. "Standar Portable Fire Extinguishers". (NFPA 10)

Pedoman Daerah. "Pedoman Pemeriksaan Keselamatan Bangunan Gedung”. (PD-T-11-2005-C). 